Archives de sciences sociales des religions

176 | octobre-décembre 2016

Bulletin Bibliographique

\title{
Karim Schelkens, Jürgen Mettepenningen Gottfried Danneels.
}

Anvers, Éditions Polis, 2015, 542 p., biographie

Étienne Fouilloux

\section{OpenEdition}

\section{Journals}

Édition électronique

URL : http://journals.openedition.org/assr/28337

DOI : $10.4000 /$ assr.28337

ISSN : $1777-5825$

Éditeur

Éditions de l'EHESS

Édition imprimée

Date de publication : 31 décembre 2016

Pagination : 385

ISSN : 0335-5985

Référence électronique

Étienne Fouilloux, « Karim Schelkens, Jürgen Mettepenningen Gottfried Danneels. », Archives de sciences sociales des religions [En ligne], 176 | octobre-décembre 2016, mis en ligne le 20 juillet 2017, consulté le 23 septembre 2020. URL : http://journals.openedition.org/assr/28337 ; DOI : https:// doi.org/10.4000/assr.28337

Ce document a été généré automatiquement le 23 septembre 2020.

(C) Archives de sciences sociales des religions 


\title{
Karim Schelkens, Jürgen Mettepenningen Gottfried Danneels.
}

\author{
Anvers, Éditions Polis, 2015, 542 p., biographie
}

\author{
Étienne Fouilloux
}

\section{RÉFÉRENCE}

Karim Schelkens, Jürgen Mettepenningen Gottfried Danneels. Anvers, Éditions Polis, 2015, 542 p., biographie

1 La sortie d'un tel livre peut étonner, quand on sait la frilosité de l'Église catholique en matière d'accès à son histoire récente. S'agirait-il d'une biographie de complaisance, à caractère hagiographique, sur un prélat qui est certes retraité depuis 2010, mais qui est toujours bien vivant? Parcourir ce fort volume suffit pour répondre par la négative. Il est certes le résultat d'une commande, mais les deux jeunes universitaires qui l'ont rédigé se sont soumis aux règles de la méthode historique apprise sur les bancs de l'université de Leuven. Toutes les règles, sauf une : leur appareil critique comporte une chronologie, un glossaire, une table des sigles, une liste des sources utilisées, témoignages compris, une importante bibliographie et un index, mais pas de notes, et donc pas de référence précise aux citations produites. Karim Schelkens et Jürgen Mettepenningen remercient le cardinal Danneels de leur avoir permis « de consulter sans réserve la totalité de ses archives » et d'avoir accepté « de répondre à toutes leurs questions ", mais ils demandent au lecteur de leur faire confiance sur le respect des règles académiques dans l'utilisation de tels matériaux. Comme la rédaction du livre «a été soutenue par les avis d'un comité d'experts » (p. 7) et que son manuscrit a été relu avant publication par le cardinal, on peut parler d'une biographie autorisée, produit intermédiaire entre approche apologétique et approche critique.

2 Cette réserve de méthode ne saurait empêcher l'historien de faire son miel d'un travail remarquablement écrit et présenté qui éclaire des pans entiers de l'histoire récente du catholicisme en Belgique et de l'histoire de l'Église catholique dans son ensemble, vu le 
rôle qu'y a joué Danneels depuis sa promotion au siège primatial de Malines-Bruxelles en 1979. Le premier intérêt du livre, pour un lecteur français, est d'aborder une telle histoire à partir de la Flandre, moins bien connue de lui que la Wallonie pour de simples raisons linguistiques. Né en 1933, Gottfried Danneels est un pur produit de la chrétienté flamande, voire flamingante pour ce qui est de sa famille : il y effectue toute sa formation de jeune clerc, de l'école primaire jusqu'au grand séminaire de Bruges et à l'université de Louvain. Vite repéré pour ses qualités intellectuelles (" primus perpetuus $»)$, il termine cette formation au séminaire romain dans lequel le Saint-Siège puise les cadres de l'Église de Belgique. Un deuxième attrait de sa biographie concerne la curieuse politique de nominations ecclésiastiques dont il est le bénéficiaire : prêtre en 1957, et donc dépourvu de toute expérience d'accompagnement des hommes, il est nommé directeur spirituel du grand séminaire de Bruges à 26 ans, dès son retour de Rome; professeur à l'université de Louvain, et donc dépourvu de toute expérience pastorale, il est nommé évêque d'Anvers en 1977, puis archevêque de Malines-Bruxelles deux ans plus tard et cardinal en 1983. Si l'on suit Schelkens et Mettepenningen, il doit cette brillante carrière tant à ses qualités intellectuelles, qu'à la prudence, terme qui revient souvent dans les premiers chapitres du livre, de son jugement et de son activité.

Danneels est toutefois un prêtre puis un évêque conciliaire, qui manifeste notamment son ouverture en matière liturgique. Jeune primat de Belgique nommé par le jeune pape Jean-Paul II, il illustre le dynamisme du nouveau pontificat qui le conduit à intervenir, de façon mesurée, dans nombre d'affaires délicates, les vicissitudes du catholicisme hollandais par exemple. L'étendue croissante de son champ d'action, difficilement maîtrisable, transforme alors le livre en une sorte de chronique de laquelle émergent quelques points forts: l'intervention de Danneels, aux côtés des cardinaux Lustiger et Decourtray, dans l'affaire du carmel d'Auschwitz par exemple. On perd un peu de vue la Belgique, où la sécularisation s'accélère, en Flandre surtout, sans que les auteurs s'étendent beaucoup sur les réactions du cardinal à un tel défi. Son autorité croissante le conduit à prendre des positions humanistes d'ouverture dans divers domaines, de moins en moins compatibles avec l'enlisement progressif du pontificat wojtylien sous l'influence du cardinal Ratzinger, avec lequel Danneels entretient des rapports complexes. Il participe à partir de 1996, aux côtés de ses amis Martini, Lehmann ou Kasper, aux réunions épiscopales informelles de Saint-Gall, dans lesquelles leurs adversaires voient une manière d'opposition à la ligne néoconservatrice romaine (intéressant chapitre 24, p. 445-458). Aussi n'est-il pas ravi de l'élection de Benoît XVI à la chaire de Pierre en 2005 et fait-il figure de grand électeur du cardinal Bergoglio en 2013. Il se reconnaît mieux dans le pape François que dans son prédécesseur, mais sa retraite est ternie par les affaires de pédophilie dans le clergé belge, sur lesquelles il ne s'est pas montré assez vigilant.

4 On aimerait certes pouvoir vérifier sur pièces nombre de précisions et de jugements des auteurs. Telle quelle pourtant, cette biographie est passionnante tant pour sa restitution d'une des grandes figures cardinalices contemporaines que pour ce qu'elle apporte sur l'histoire de l'Église catholique au tournant des $\mathrm{XX}^{\mathrm{e}}$ et $\mathrm{xxl}^{\mathrm{e}}$ siècles. 